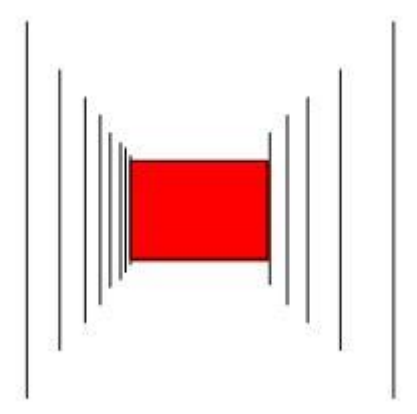
Centre for
Building
Performance
Research

\title{
Social Elderly Care Facilities
}

Investigating generational differences

in the needs/requirements for social elderly care facilities in New Zealand.

Lily McDougall

Nilesh Bakshi

Stephen McDougall

Andre Brown

Research and publication by the

Centre for Building Performance Research,

Victoria University of Wellington.

In partnership with:

Studio Pacific Architecture.

February 2020 
Edition information

ISBN 978-0-475-12435-7

Authors: Lily McDougall, Nilesh Bakshi, Stephen McDougall, Andre Brown Research Assistant: Lily McDougall.

Partnering Researchers: The Research Group at Studio of Pacific Architecture

Report title. Social Elderly Care Facilities: Investigating generational differences in the needs/requirements for social elderly care facilities in New Zealand.

Centre for Building Performance Research, Victoria University of Wellington,

P.O. Box 600, Wellington, New Zealand.

Phone + 6444636200 Facsimile + 6444636204 


\section{Table of Contents}

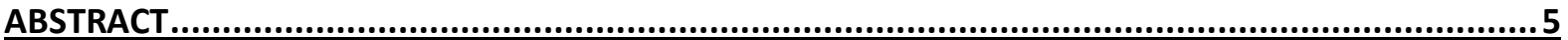

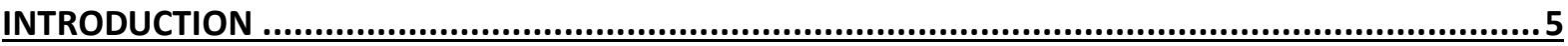

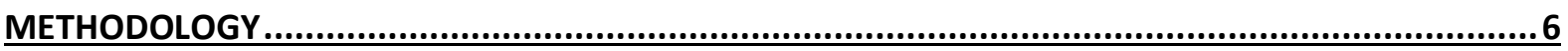

USER PERCEPTIONS AND PREFERENCES $\ldots \ldots \ldots \ldots \ldots \ldots \ldots \ldots \ldots \ldots \ldots \ldots \ldots \ldots \ldots \ldots \ldots \ldots \ldots \ldots \ldots \ldots \ldots \ldots \ldots \ldots \ldots \ldots 7$

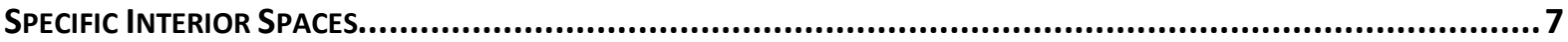

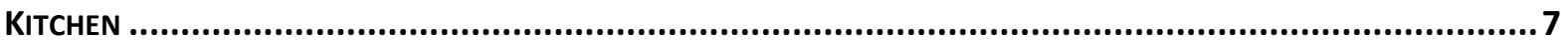

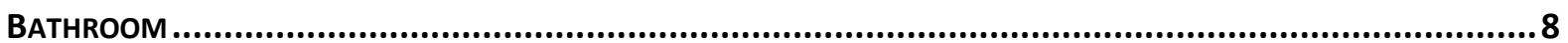

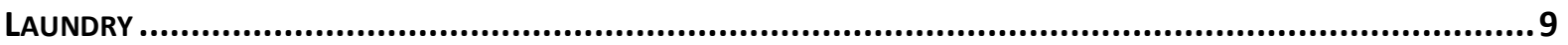

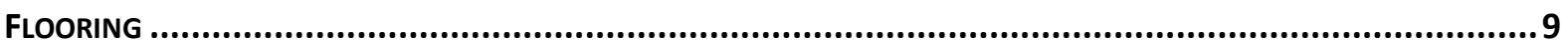

SPATIAL CONFIGURATIONS $\ldots \ldots \ldots \ldots \ldots \ldots \ldots \ldots \ldots \ldots \ldots \ldots \ldots \ldots \ldots \ldots \ldots \ldots \ldots \ldots \ldots \ldots \ldots \ldots \ldots \ldots \ldots \ldots \ldots \ldots \ldots \ldots 9$

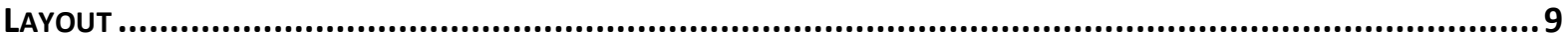

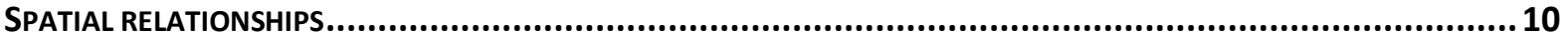

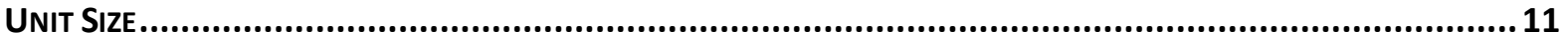

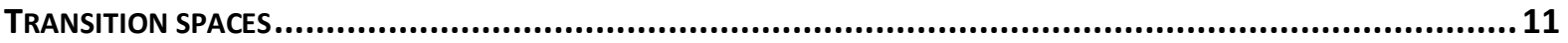

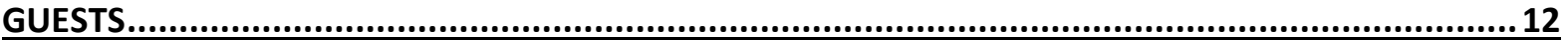

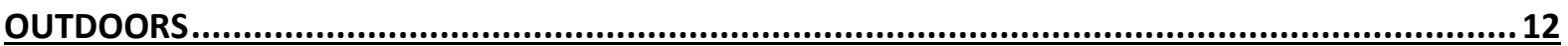

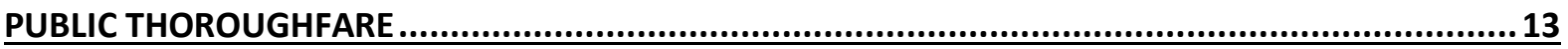

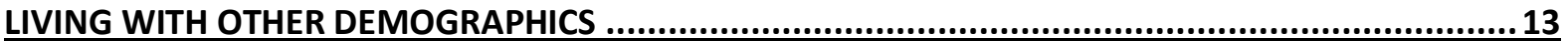

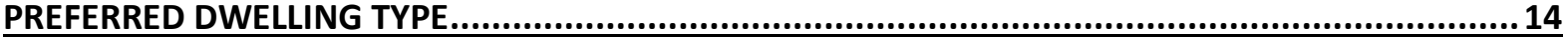

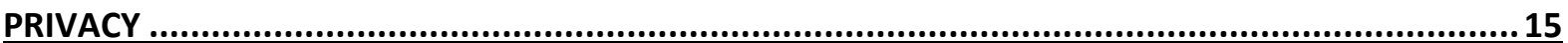

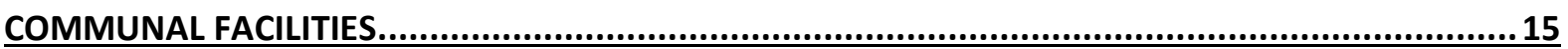

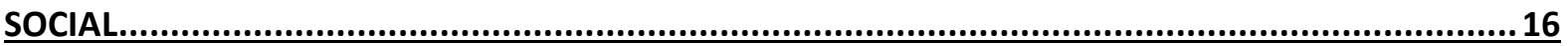

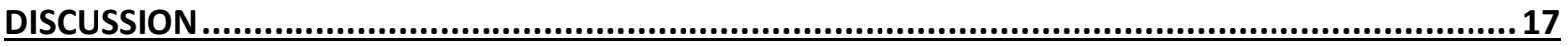

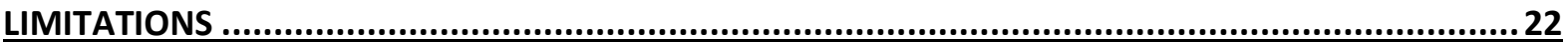

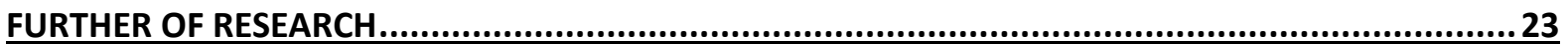




\section{Abstract}

In New Zealand the core demand for social housing is greatly made up by elderly people, with 270,000 older people projected to in need of social housing by 2030. A market driven response through the supply of social housing for elderly is necessary to combat this issue. This project is based on the logical progression from the preceding phase (phase 2) of this research. The research posited that there may be a potential for households comprised of different age groups and generations to have specific user preferences. Therefore, the aim of this research aims to identify how user perceptions differ across multiple generations in order to recommend a best practice model for designing social housing facilities for future generations. Working with a medium-scale, research based architectural practice, the objective of this paper is to conduct a cross generational study to understand the preferences of future users of elderly facilities, to allow the market to drive how elderly care facilities are designed going forward. This paper uses a qualitative case study approach to examine the preferences of thirty Wellingtonians, in conversation-based focus groups. The study finds that user preferences do not tend to be correlated with generation, but a person's stage in life.

\section{Introduction}

The term social housing has become a more relevant phrase in this era where there is more social equity. While at the moment there is a lot of research on elderly housing, understanding the quality and lived experience of social elderly care facilities is limited (McDougall et al., 2019). This research project is investigating the generational differences in the needs/requirements for social elderly facilities in New Zealand. The scope of the project is based on the logical progression from the preceding pilot studies completed in phase one and two. The first phase was a literature review which identified globally researched interventions for designing elderly housing. The second phase was a qualitative case study examining the living experience of 10 elderly people living in local authority rental housing in New Zealand. While the findings identified some key design considerations for future social elderly housing, much of the insights gained did not provide answers that were expected. Residents were less than forth coming with constructive criticism than might have been anticipated. Further, only one generation was examined. The key proposition put forward based on the findings from the two preceding studies was that future generations may have different expectations and social norms, and this will likely lead to varying preferences of spatial arrangement and requirements.

Therefore, this third phase of the research aims to identify how user perceptions differ across multiple generations in order to recommend a best practice model for designing social housing facilities for future generations. As identified in phase 2, during the next 30 years, the proportion of people aged 60 or over will increase from $15.4 \%$ in 1996 to $25.3 \%$ in 2030 (Chapman, Signal \& Crane, 1999). This suggests New Zealand has an aging population that is growing exponentially. In order to accommodate for this projected population growth, there is an increasing need to accommodate for appropriate residential housing, supporting both those who require care, although this research only focuses on those who are able to live independently. The inequality gap has grown over the past ten years as house prices have also rapidly increased, contributing to a gap between those who can afford a home and those who cannot. This has seen a rise in renters as well as an increased reliance on social welfare. Consequently, the response of social housing has become more apparent as the appropriate and necessary response. Social housing is housing assigned to people who are most in need of housing (Johnson, 2017). 
According to Johnson (2017), people aged 65 and over with limited and fixed incomes and restricted housing choices will make up a growing market segment for future social housing. The amount of people who are not wholly financially independent or are dependent on government assistance to support them once they leave employment, particularly superannuation, is ever increasing (Taylor, 2016). Statistics from Statistics New Zealand state that $70 \%$ of people aged 65 and over are earning less than $\$ 30,000$ per year, with $20.6 \%$ earning less than $\$ 15,000$. This makes it very difficult to fund a life, particularly with housing prices continue to increase. One-person superannuation allowances are among the lowest incomes across all of New Zealand (Chapman, Signal \& Crane, 1999). Further, Statistics from the Social Policy and Parliamentary Unit at the Salvation Army states that in New Zealand 190,000 older people are part of the core demand for social housing, and this number may grow to 270,000 by 2030 (Johnson, 2017). To illustrate how large this growing problem is, to provide social housing to just $25 \%$ of all elderly tenants will require an additional 30,000 units over the next 15 years (Johnson, 2017). Therefore, a market driven response that meets this demand for social elderly housing is crucial.

As the elderly population is growing exponentially, it is important to understand the preferences of future users of elderly facilities. It can be surmised that generations may greatly differ in their attitudes, expectations and values. This can be based on Kupperschmidt's (2000) definition of a generation, "an identifiable group that shares birth years, age, location and significant life events at critical development stages." It can be thought that the drivers of the differences in values are the different living experiences determined within generations. However, it is important to note that contributing to these values may be differences in culture, stage of life or housing experience. Thus it is important to gain insight and understanding into these diverging backgrounds and perceptions in order to allow the market to drive how elderly care facilities are designed going forward rather than our own, somewhat more assumption based opinions. This is particularly important as there has been little or no research to date exploring how people's past may impact their future desires for elderly housing.

\section{Methodology}

In order to systematically assess respondents' perspectives to the design critiques of their current and future living situations and facilities, a qualitative phenomenological framework guided the research. A qualitative approach was chosen as it enables the researches to understand and gain insights into people's backgrounds and also the 'why' behind certain perceptions (Stewart-Withers et al., 2014). Phenomenology is an inductive analysis that allows for ambiguous human views. It has been described as a "philosophical movement based on a self-critical methodology for reflectively examining and describing living experiences" (Reeder, H. 2010). It allows the research to answer questions about understanding an experience from those who have lived it. The aim of phemenology is to make explicit certain types of claims, while also uncovering the subjective truths of the claims. This was important in the focus groups and findings as it was necessary to reflect on respondents' preferences and understand the meaning and causations behind them. The research was focused on a case study of six focus groups. The sampling for this research was random and purposive. The first round of focus groups was a random selection of a group of six and a group of four people from Studio Pacific Architecture who were available on the certain date and time. This was to avoid any bias infiltrating the beginning of the findings.

Based on the demographic, age and sex of those in the first groups, the following four groups were purposely selected, based on more defined, profiled groups. This was to further enhance and analyse how living preferences change and help determine the legitimacy of theorised correlations. For the 
focus of this study, 30 respondents were spoken to with different occupations, ethnicity, housing background, gender and an age bracket of 21-61. Of these, 20 were employees at Studio Pacific Architecture, with roles from technology manager and human resources advisor, to senior architects. Six participants were Architecture post graduate students working as summer researches for the Studio and four worked for a project development company. It was important to have people from a diverse range of work experience and age groups to vary the observations allowing for architectural insights as well as non-design perspectives. However, the people spoken to all had an informed and experienced perspective of design and the built environment, which was beneficial as they were an educated population. Semi structured, face to face interviews were conducted by a research assistant, and an expert architect participated as the scribe. It must be recognised that the focus groups were not necessarily from the demographic group in research. However, the purpose of the study is to develop an understanding of those who will enter elderly housing in the long term.

The methodology and plan for the research changed direction slightly in the beginning phase. Initially it was thought a series of pilot tests would be conducted to establish some potential correlations, in order to direct the next step of the study. Following this, a second round of focus groups would be conducted consisting of people of varying ages living in social housing today. However, based on the level of detail and patterns discovered within the initial groups the direction and plan for the research was re considered. It was decided that enough correlations and causations had appeared and a sample size of 30 was large enough, particularly considering the time constraints of the study.

Analysing the respondent's transcripts involved a series of steps including preparation, organisation and categorisation before arriving at presentation of findings. Emerging themes were coded on a spread sheet in relation to themes that had also emerged from the preceding stages of this research.

\section{User perceptions and preferences}

\section{Specific Interior Spaces}

\section{Kitchen}

Twenty-five people spoke about cooking and spending time in the kitchen. Of this, 15 people said they enjoy cooking now and want to continue cooking later in life. "You want to feel independent and not rely on someone to make a delivery" (participant 6). One other participant noted they do not enjoy cooking but would like to in the future. Five participants liked the idea of a communal kitchen. Participant 2 who currently lives in a flat with her friends noted that once a week they do a flat dinner. She would love to do more of these if she had more time and money and notes at. an older age she may have this, so may be interested in a communal kitchen. Participant 18 expanded on this point, "Tea and coffee kitchenette in living space. One element, no oven, microwave... Give up your kitchen but with access to high-spec communal kitchen that you could use when needed." Participant 3 also spoke to having a kitchenette, saying if you couldn't cook that well it would still be nice to have a kitchenette. This gives insight into the least amount people are willing their spaces to have. Seven participants liked the idea of some other form of dining experience, such as a delivery service or a local pub, "to break up cooking for yourself" (participant 15). Participant 16 and 18 commented on the fact that cooking for one person is often less easy, with 16 saying it is "uninspiring". Participant 18 also suggested a food box delivery service, such as "my food bag" which is cooking for yourself but made easy. Three other participants also spoke about this however referred to a more finished version of "my food bag", as 
after watching their grandparents struggle, they perceived this as still too difficult or labour intensive. Five participants stated it would depend on their ability, often mentioning their experience with parents/grandparents developing arthritis and other impairments thus finding it difficult and stressful to cook. When considering the least amount needed for a unit, it is necessary to still have some form of kitchenette and options to allow people to feel as if they have control.

Twenty-five people spoke about ovens. Twelve responded they would want an oven in the future. Five participants said they may prefer a smaller convention oven, however one of these participants noted it is hard to know what your preference will be. Participant 27 who was in favour of a convention oven noted that often microwaves come with negative connotations, suggesting that a combi oven is better. Seven participants said they would prefer a wall fitted oven, particularly mentioning they are better for people with less agile backs. Participant 3 also mentioned an oven that sat on the bench. Participant two first noted, "I would take what I can get," before agreeing that a wall fitted oven would be her preference. Five people liked the idea of a half-sized oven. Participant 8 currently has both a half size and full-size oven and uses the half size more. Participant 28 stated, "a full-size oven is a waste of space for an elderly person." Participant 27 also agreed, and both were referring to their grandparents' difficulties. This again suggests background experience with these points of discussion shapes preferences. Further, participant 28 noted the importance of a stove top. Three participants noted the style/size of an oven would depend on how many people they are living with, "when living by yourself, firing up a big oven may not make sense" (participant 2). Two participants said their preference would depend on their capabilities. In total, 10 participants explicitly mentioned they would be content without a full-size oven, but some other form. Only one participant said they want a full oven no matter how many people they live with. Thus, it can be reasoned that a full-size oven is unnecessary.

\section{Bathroom}

The most favourable option when considering bathrooms was a main bathroom with a separate toilet, with $33.33 \%$ opting for this option. One participant mentioned the main bathroom having a toilet and then a separate toilet off it, although noted that this may be the ideal family house, if it was just a couple or one person occupying the dwelling then a bathroom with one separate toilet would be fine. Thirty percent of participants commented on the importance of having a separate toilet space for guests to feel comfortable, such as a toilet accessible through the lounge space. Although participant 18 identified that having a toilet opening off a living space is not ideal.

Eight respondents noted they would like an ensuite, with three of these noting it is important for convenience/accessibility. Two further participants mentioned the importance of accessibility. However, one respondent in favour of ensuites stated they are unnecessary if there is only 1 or 2 people in the unit. Six of the eight who responded in favour of an ensuite were all under the age of 30. Participant 4 was Caribbean and made a cultural observation. He asserted that it is a Kiwi thing to have three bedrooms and only 1 bathroom in a house, and that it is weird. He stated it is particularly important to have the choice when you are older. 30\% (9) expressed they did not and have never liked the idea of an ensuite, with some respondents even stating they "hate" them, or "feel very strongly" about them. Reasons for this included steam or making things in the bedroom damp, disliking a toilet so close to where you sleep, noise, or them being an inefficient use of space.

Seven participants liked the idea of a dual access bathroom, with one door to the bedroom and one door as a 'main' entrance to the hallway. Participant 5 stated this was a flexible approach. However, a further 
six participants expressed they did not see the appeal of a dual access bathroom. Participant 14 noted they create too many issues with people walking in on other people and other participants agreed with this statement. Participant 4, 9 and 25 noted they have a preference for two bathrooms. Seven other participants felt strongly about only needing 1 bathroom. Two participants mentioned multiple bathrooms are unnecessary if only 1 or 2 people in the unit. Participants 1,2 and 3 commented on not wanting to maintain multiple bathrooms when older.

In conclusion, it can be suggested that ensuites are unnecessary when designing for elderly homes, particularly with limitations. A main washroom with a separate toilet is recommended.

\section{Laundry}

This topic raised some discussion and reflections within participant groups, "it is a hot topic right now, whether laundry can be in a communal space or whether this is gross" (participant 18). Twelve participants said they would like their own laundry. "You need your own laundry to retain dignity (regarding health problems)" (participant 1). Participant 3 was one of these in favour of her own space however she noted it may be 'fun' doing it in a communal space. Participant 5 said she would prefer to have a communal kitchen than a laundry. These participants ranged from 21 years to 54 years. Three participants said they would not mind it to be in a communal space, however they made some justification/requirements for why. Participant 21 said if he was then able to not buy his own washing machine. And participant 25 commented only if it was a nice facility. Al three were under the age of 25. Five participants mentioned they had had experience with communal laundry's, and all five did not want it again. Reasons for their bad experiences included that it is a pain as you have to be constantly checking on your laundry to make sure no one puts it on the ground once it is finished its cycle so they can use the machine, un hygienic nature of them, and for one participant it took a whole day out of your time to do as the washing quarters were too far away. However, this participant then added that perhaps if you just shared with adjacent apartments then it would be okay. It can be suggested that it is best to install each unit with their own small laundry facility.

\section{Flooring}

Only 14 responses were captured for this question. $64 \%$ stated they would want wall to wall carpet in the living rooms. Of this $64 \%, 21.5 \%$ noted how hard surfaces are a danger for falling over. And a further 2 respondents with this perspective noted there is something "cozy" about carpet. Further, participant 26 who was also in favour of carpet mentioned, "Carpet can be hard to keep clean, so it needs to be both durable and comfortable."

Four participants said taking cleanliness into consideration is important.

Participant 7 said they would like hard surface floors and said when they lived with their father in law, they had to get rid of their carpet quickly, comparing elderly to the same way children make a carpet messy/dirty. Participant 8 pointed out the trip hazard with area rugs.

\section{Spatial Configurations}

\section{Layout}

Thirteen participants spoke about the potential of having too much space. Two participants said they anticipate they would want to downsize their space when they are older. Participants 9 and 10 
commented on lounge spaces being a "hassle", with participant 10 mentioning "If a room is collecting stuff, then you have too much space." They were both advocates for ensuring spaces are used efficiently. Four participants spoke to making sure the size of the lounge space is proportionate to how many people are living there. One participant referred to their current living situation, where they live with three others and they do not use the lounge much so "it is a waste of space." Five participants spoke about appropriate size bedrooms, "a lot of lounge spaces are often too large at the expense of bedroom space where you can only fit a queen bed and a nightstand. I would prefer a slightly smaller lounge if there is more space to walk around the room" (participant 15). Participant 26 also mentioned ensuring bedrooms are big enough, "it is especially important as an elderly person to have good mobility around the room." Participant 23 and 24 wanted their kitchen spaces to be bigger.

Only six participants spoke about the layout of the living room. Three of these commented on the importance of having an outlook. Participant 1 referred to the prospect refuge theory, "nice to have your back to a wall to see out, but still withdrawn from the scenes outside." Participant 2 suggested something similar, "Spying (observing) and being able to feel the presence of those around you." Participant 6 noted it is important when having open windows that you do not feel watched. Two participants commented on being able to filter the sun.

Five people wanted a front and back door if they had a front garden and a back garden. Participant 2 said "without a back door then the flow of a house is lost." Participant 6 said having a back door into an outdoor space that is your own private space is important. Participant 26 was the only one who spoke to not needing a back door. They said as long as there is a means of cross-ventilation in the dwelling then it would be okay.

\section{Spatial relationships}

This discussion point brought about varying perceptions. Thirteen participants said they enjoy an open plan living/kitchen/dining area. Three of these respondents said it is nice to be able to separate the rooms if need be, "being able to designate an open plan area is good, so you can leave people to use the space if they want" (participant 15). All bar one of those who suggested this design were under the age of 40 which suggests it could be a generational preference. Six respondents stated their preference for an open plan kitchen/dining, but a separate living space. Participant 18 noted "Kitchens can be messy spaces with a lot of energy." He thought it is nice to have "a snug where you can relax and be quiet." Participant 10 also liked this idea however reflected on his own original opinion saying, "if you are on your own you don't want to be tucked away in the kitchen, ultimately it is about the person in the kitchen feeling involved."

Three participants said the relationships between spaces may depend on how many people are living there. One of these noted that if it was just one person occupying a unit, a spare room would be unnecessary. They would only need a bathroom and then a large living space and could just sleep on the sofa. However, he said as a couple you may need separate rooms. Three others commented something similar, stating in the future you may need fewer private rooms. However, two different participants suggested potentially wanting more privacy in the future. These conversations may illustrate that people found it difficult to envision themselves with limited space. Yet, some narrative suggests that when people were realistic about expenses for the sake of this research, they were willing to downsize or sacrifice rooms. Nine participants noted bedroom privacy is important. Participant 8 stated she once visited a person who only had a sliding door between the lounge to her room and this 
was a bit confronting. Participants 21, 22 and 24 mentioned the appeal in high ceilings. "A high space is comfortable and feels a lot bigger that it is" (participant 24). However, participant 24 also stated that bedrooms are less comfortable with high ceilings, thus it was only preferred in kitchen, dining, lounge, bathroom spaces. Participant 21 noted that his flat mates had admitted they do not like high ceilings in living spaces, shifting from a $2.7 \mathrm{~m}$ lounge ceiling to a $2.4 \mathrm{~m}$ and preferring it.

\section{Unit Size}

Four participants commented they would like a 75-90sq $\mathrm{m}$ unit in the future. Two others stated $74 \mathrm{sq} \mathrm{m}$, and a further two suggested 40-50sq $\mathrm{m}$. No one commented they would need bigger than $90 \mathrm{sq} \mathrm{m}$. Nine participants made comments about how they could downsize their units when they are elderly. Participants 8 and 24 said creating more efficient uses of spaces is necessary, "making the space feel larger through design" (participant 24).

Thirteen participants said they would like 2-bedrooms in their units. It is interesting to compare this to the earlier discussion about having a spare room for guests to stay, where 12 responded it is important to them. The one extra in this conversation was participant 9 . They originally commented, "it is crazy to have a spare room that would only be used once every few years, so another model, as opposed to a whole other permanent room in the house would be good." In this discussion point he said, he would like a spare room, but it could double as a study or a second living room. This may suggest that the discussion within focus groups can have large impacts on individuals projected preferences. Three participants said they would like multiple living spaces. Participant 13 commented "I ideally would like a casual area and a nicer lounge area." Participant 14 also suggested this, "multiple lounges with spaces you can get away from everyone." Within this discussion group, participant 12 reflected on her own experience of having multiple lounge spaces, and said she found her family gravitated to only using one space.

\section{Transition spaces}

Only 14 people spoke about transitional spaces. All those stated a covered/sheltered space is important. Participant 5 stated "the more you address rain, wind and sun, the more likely it is to be used." Participant 20 mentioned having options, and participant 10 reiterated this, commenting "the ability to have the door open but still feel private." Reference what he drew. 21 said a transitional space is important as a utility area (e.g. drying clothes), and 13 and 15 said it is nice for somewhere to entertain. Participant 7 also noted that layering is good.

Eight participants said they would like their mobility scooter to be parked by the front door. Participant 25 noted this proximity would be a security thing. Reference was made to a successful design for mobility scooters with the Marlborough district council, it was a bolt on mobility park with a bench and roof. Three participants noted mobility parking would need a covered area. Seven participants thought a mobility scooter would need a transition space/mini garage. Participant 4 who is around elderly people often said this is required as parking outside can also be inconvenient, he suggested a mud room style. Participant 5 said something along the same lines, "somewhere where you can take off your coat, park your scooter and then enter into the rest of the house." Some participants questioned how mobility scooter parking would work in apartments. One noted that some doors at apartments are very heavy and difficult to use, so need to take this into consideration. Participant 24 suggested having a park for all the scooters in the complex. 


\section{Guests}

Twelve participants said a spare room is important to them, "I would value a spare room as it gives the guest their own space" (participant 25), and "I like to make my guests breakfast and have the whole experience" (participant 7). Of these, majority (77.8\%) grew up in a standalone house. Eight participants commented a spare room is not so important to them. Participant 13 (age 30) said when she flatted, she had lots of people come to stay and they were fine in the lounge as long as the lounge was large enough to accommodate. Participant 21 who is currently in a flat said something similar to this, "there is usually an expectation that people will be accommodated for in the lounge, a fold out bed always works." Seven out of eight of these participants are under the age of 37. Participants 22 and 23 both would prefer a spare room, however if it would cost more to have a spare room their preference would change. Both these participants are exchange students in NZ. A further eight participants mentioned that it would bother them if they had a spare room that was only sometimes used. "The cost of having an extra bedroom for those infrequent visits is not worth it" (participant 18), "a spare room can become a bit of a junk room" (participant 19). Four of these participants had not explicitly stated that a spare room is unimportant to them, however it can be assumed after making this comment, they can be categorised as not wanting a spare room. So, in conclusion 12 participants believed a spare room was unnecessary.

Seven participants said an alternate option for guests could be appealing, such as a communal unit/room that you could book out if you had guests staying. Six out of seven were respondents that had stated a spare room was not important to them. Of these seven, five had had experience with using a different type of model for guests. Such as a campervan for guests or a sleepout. One participant said they booked an air bnb or hotel for guests when they would come to stay, noting "I like that they come stay but do not have to be right in my pocket." No one asked opposed this idea. The option of a 'Japanese style' living room/more functional open space was brought up by three participants with the idea you could break it up and use screens to create different spaces or close it off for when guests come to stay.

\section{Outdoors}

Eleven participants stated they would like their own garden to use. "I will probably be a bit bored so I would like a garden to fill my time" (participant 18). Three of these participants noted how they do not currently do much gardening but could see themselves potentially gardening more in the future. This highlights how people may find it difficult to project an accurate representation of themselves in the future and thus answer from a 'this is what I would like myself to do in the future' point of view. Five participants said they would like their own garden for visual purposes only. A different group of eight participants stated it is important to them to have an outlook, "there is an importance of being connected to the world beyond your boundary." (participant 8). Four participants noted they would like a relatively small garden in the future, with comments such as "just enough maintenance" (participant 10). This led to discussions again about having a small private garden space with access to a larger public green space. Fourteen participants stated they would enjoy this (this number includes those who had previously stated it). However, participant 20 said she was unsure if in her old mind she would want this but thinks her young mind is telling her old self that she should want this.

Participant 9 referenced the daisy-chain of big park spaces in London, mentioning NZ cities do not tend to have this. Further he brought up the layout of, "a gradient that goes from small (garden) next to unit, to larger that is part of the complex, and then something even larger associated with the whole neighbourhood." Participant 6 and 7 liked this approach. Six participants referred to their own recent 
experiences of not having access to a garden, and how it makes them just want any green space. Participant 20 moved from their old apartment for the sole factor of wanting outdoor space. Participant 21 who currently has next to no outdoor space says he would not care if it was public or private, he just wants more. This suggests experience influences perspectives. However, participants 22 and 23 said they would prefer to have their own green space. Participant 23 who grew up in high density dwelling in China said the complex had a central garden which she did not mind, but if there was a chance, she would prefer her own garden area. Three participants mentioned wanting a permaculture environment. Only one participant said they would like AstroTurf, although quite a few others stated firmly that they did not want it.

\section{Public thoroughfare}

$39 \%$ (7 out of 22) said they would not mind the public walking through the dwelling area as it would allow you to live vicariously, provide entertainment and help connect you to the wider community. Participant 5 commented, "there is a morbid feeling of being in an elderly complex. There is an animation that the public brings and a different way of life. It could be healthy. It could be amazing." "If I was less able-bodied it would be a good way to bring the community to my doorstep" (participant 26). Participant 16 referenced an elderly community in Gisborne that had a public bus route that went through neighbourhood that connected these people to the wider community. Twelve different participants noted they would not mind this depending on the design of the environment. "As long as the designed environment enables it, rather than someone just running through the back yard" (participant 10). Participant 30 talked about the importance of ensuring an overview of the street to keep potential troublemakers in check.

Four participants commented they would prefer it to be closed off, particularly for security/safety reasons. The majority of participants had a positive perspective towards the public, as long as it is purposeful.

\section{Living with other demographics}

Living close to others was a well-considered point of discussion among the participants.

An overwhelming $96 \%$ (29) of participants commented they currently like to live in an integrated way with families and other demographic groups around. Participant 20 (age 21) noted it is refreshing to have other age groups around as it puts your personal life into perspective. Participant 2 said in the future they would like but not now. Of the twenty-nine, twenty-six commented they would still like to live in an integrated way with other demographic groups when they are elderly. The following narrative gives a richer understanding to the perspectives behind this response. Participant 9 mentioned that "diversity is the key to successful neighbourhoods". Participants 11 and 14 commented their preference may change depending on how old they are, noting when they get older ( 80 years or so) they would want people of a similar age and mindset around. However, participant 11 at first commented she likes having the energy around of younger kids yet then reflected on her response after hearing other people's comments.

Participants 7, 9, 10 and 15 all commented they would like other demographics around yet reflected to say there would need to be a commitment to common values among those different demographics. Participant 19 stated if it was in a complex then it should have an element that incorporates a broad mix of society. Participant 9 referenced 'Quaker' communities and stated that it would only take one family 
to ruin the experience. This also led to discussion about not understanding the current retirement village model of all elderly, referenced by both participant 10 and 19 saying, "one size doesn't fit all".

Participants 12 and 13 did not like the idea of having other demographics around when they are older, stating when you are older you would want to be around people of your own age and stage in life. Participant 12 expressed that there are already different abilities in an older age group so that would give enough of a mix, and further they both agreed grandchildren around would give enough of that exposure to children. It is important to note these responses are from one focus group, thus this could have impacted their preferences. Six participants also mentioned the appeal of children within elderly complexes, the pilot studies done, and how important this seems. Participant 11 noted she enjoys having the energy of children around and participant 8 even suggested having a childcare centre within the rest home, where the elderly are the caretakers. It seems that living in an integrated way with other demographics yields positive thoughts, but once again the values and mentalities must be considered.

\section{Preferred dwelling type}

A range of responses were brought about from this point of discussion. Five respondents stated they would like to live in an attached or town house model. "Close to your neighbours but not too close, as no model fits all" (participant 5). Some spoke to how in a standalone/town house "you can make it more of your own space" (participant 25). Three participants said they could see themselves moving into an apartment. Only one of these had had experience with apartment living. Six respondents stated they would not like to live in an apartment. There were several reasons for this. Some suggested apartment living could be isolating, that they seem to give off a "low light insular existence". (participant 15) or because people like a free-hold title, not to be a part of a body corporate. Four participants stated they wanted choice, to be close to people or not, in their dwelling spaces. "Having a 'shell' that you can retreat into when needed." (participant 4).

Thirty three percent spoke about wanting access to outdoors in their future dwelling spaces, and four mentioned the need for privacy. A further four participants commented on wanting the ability to have social interactions. Participant 1 noted, "As you age you are less able to get out so need to bring people closer to you." Participant two (age 25) stated she has never lived alone before and enjoys the social side of flatting. This experience may have largely impacted her preferences. Six participants spoke about wanting to live with people with the same mindset, or even friends.

There was some conversation around who you would be living with and how you may get on with these people. Participant 4, from Jamaica, presented his diverging experience/perspective based on his cultural past. He found it unusual when he moved to New Zealand that you would flat with strangers' side by side. Whereas in Jamaica you only live with people you know. He then compared living with someone to being in a relationship with them, living with them means you have to engage with their emotions and issues. He stated when you are elderly you may be too old to deal with this. Participant 1 expanded on this exclaiming when you are young and flexible the flatting experience is fine. However, if you are older you are not as flexible or lenient, thus you may not want to live with people you have not known long term. Participant 2 also commented that in elderly age there are people who are less able and harder to interact with, thus it may lead to frustrations when dealing with these people. This is an interesting insight about trying to combine people in complexes with the same values. 


\section{Privacy}

Eleven participants responded that they would want their units to feel private. Participant 11 and 13 noted you do not want people being able to look into your house and participant 9 commented that overlooking from neighbours can be an issue. It was also noted that for toilet privacy there needs to be more than only frosted windows.

$56.7 \%$ (17) of participants noted they wanted graduated privacy or a choice of privacy. Five respondents noted they wanted graduated privacy in terms of being able to acknowledge/talk to people as they walk past, or having a more public outdoor space, but also having the ability to retreat to more private areas of the dwelling. Two respondents noted the living and outdoor areas could be less private with the bedroom a more private space. Participant 25 and 30 stated the amount of privacy is dependent on the area you live in or the stage you are at in your life. In the inner city you would want more privacy, yet suburban areas may feel different. Participant 18 noted a sense of privacy may be more important when older.

\section{Communal facilities}

Eight participants expressed they would like communal gardens now. Six other participants stated they did not want access to this now. Participant 10 (age 34) commented this was because they would not have time to commit to one or contribute to upkeep. Nineteen participants asserted they would like access to communal garden facilities in the future. Of this 19, 15 stated they would want access to all communal facilities and gardening. And of the 19, 14 stated they would like access to these facilities for assisting and encouraging the ability to socialise. For example, respondent 15 stated a shared pool or garden facility would be a more natural way to interact with someone as opposed to at a mailbox. Respondent 24 commented this is really important as it provides stimulation and entertainment for an elderly person's day, otherwise they may spend a lot of time at home. However, participant 27 had a different perspective, saying they do not think they would use a communal social space as they do not have the type of personality where they feel confident enough to go up to others and become friends.

Respondent 6 noted he would not like having to go through fences and gates to access these facilities as it feels a bit 'elitist'. Respondent 20, (age 21) compared being a student with being elderly as don't have as much money or space, whereas stated perhaps in her mid-life she would prefer her own immediate space with more money to upkeep her own garden. Another participant related this question to cost. They currently have a shared rubbish room and shared gardener in their apartment. They like this body corporate model as they do not have to worry about these things and thinks this would also be useful for an elderly person. Participant 19 said a similar thing and mentioned it could also be useful sharing garden equipment.

Nine participants noted how communal facilities come with conflict/tensions, particularly when older. For example, participant 9 said it would depend on who maintained it, as a roster system would fall down and create tensions. Participant 3 also mentioned this commenting that old people get "rather set in their ways" and would get upset if others touched their garden. Further, five participants mentioned how in principle the idea of a communal space is nice but they were unsure how often they would actually be used. Participant 1 noted that community gardens tend to be looked after by those that want to be involved and others just drop away. He suggested a "graduated" ability to involve yourself. 
This led to another point of discussion about having a small private garden with access to a larger communal green space. Five participants noted they would like this, however not all participants touched on the subject, until later under question 2a. Participant 21 and 25 stated they would not mind if there was only a communal outdoor space as long as it was nearby.

Participants 17, 18, 19 and 27 commented on communal facilities to encourage hobbies, such as Tai Chi or workshop facilities. Participant 18 suggested giving the opportunity to do the things you have always wanted to do, and that the communal aspect means you can share equipment. Respondent 19 provided their own experience with communal lounge spaces in elderly facilities stating people would clash over noise or uses and it did not really get used that often. He noted the space was really only used when there were activities organised, or people used the croquet lawn outside. While there were conversations around the conflicts that come with communal facilities, the majority of respondents were in favour of them, particularly if there are also private spaces.

\section{Social}

Seventeen participants responded that it is currently important to them to be able to easily socialise or communicate with their immediate or close neighbours. The generation/age of these respondents ranged from 21 (generation Z) to 57(baby boomer). Reasons that constituted this importance included: eight participants noting it was important for security reasons. Seven participants noting it is important for comradery. Of this 17 , six participants commented they did not necessarily need to be great friends with their neighbours, but a casual, friendly level of interaction is nice. Of this 17, five participants commented they had an expectation to get to know their neighbours, with participant 2 even commenting they were upset when their neighbours did not want to foster a relationship with them.

Nine participants commented having a gradient/the choice to socialise and communicate with neighbours is important, "it is important and possible to create an environment where you can have both" (participant 6). Respondent 7 who grew up in the US commented they miss the layout of suburban American streets, with open front gardens that encourage social interaction on the street. They noted it was a very New Zealand thing to have high $1.8 \mathrm{~m}$ fences. Six other participants also noted they would like this layout of the front of properties. Respondent 17 who grew up in Argentina also commented on her past, saying she lived in a private dwelling with shared open spaces that children could play. She noted "all of the street was their playground" and their parents/grandparents could sit on the porch and watch them. She says she misses this environment. Participant 10 referenced their own style property (include drawing) with high back fences, but low or no fences at the front of the property. They said they enjoy this layout as it enables them to often interact with neighbours when at the front of the property. This illustrates the desire for graduated privacy/sociability. It was observed that past experiences tended to be important in terms of allowing for insight into preferences. In total, $38.5 \%$ of participants commented on liking a layout of an open front garden that allows for a gradient of sociability with the ability to retreat back to other more private spaces. Of these in favour, the age ranged from 26-57. The majority consensus was that people would like an open layout if they have other areas that are private.

Participants 12,13, 14 and 29 commented they would not like this open style of a neighbourhood. One commented you need enough privacy so that people cannot see your house and participant 12 mentioned their mother's elderly complex noting they all have front gardens however you never see people out there, they usually retreat to their back gardens. Participant 14 referenced Britomart street housing 
which is quite open claiming she would never like to live like this. Participants 13, 14 and 21 also commented it is currently unimportant to them to socialize with their neighbors. All three plus another five also stated they had no expectation to do this. Thus $26.6 \%$ of participants had no current expectation to get to know their neighbours. Reasons for this included moving houses frequently and not having the opportunity to get. to know them. However, five of these participants responded they would like to get to know neighbors in the future. Only three participants stated they did not think it would be important in the future. Therefore, it can be reasoned that establishing connections with neighbors in elderly complexes is important.

\section{Discussion}

The research identified various aspects of design considerations for elderly housing as important. The ability to cook in your own kitchen was raised as important, and at the least a kitchenette should be installed in each unit. A delivery service for meals, or some local dining place is also be suggested to accommodate for varying levels of ability. Wall fitted ovens are preferred, with participants referencing the ease of accessibility. A full-size oven is not essential and installing convention or half size ovens appears sufficient. This is compatible with the results from phase 2 of the study where sixty percent of occupants did not use their free-standing ovens provided in their units and bought their own smaller cooking appliances such as convection ovens or air fryers.

Ensuites were a point of controversy. Based on discussions it can be concluded that they are unnecessary for a one or two-person unit. This was consistent with findings from phase 2 where occupants said ensuites were unnecessary. Dual access bathrooms are not ideal, and the most favorable bathroom option appears to be a main bathroom with a separate toilet. This ensures somewhere private for guests which emerged as important to participants. A front and back door is recommended, and the importance of having an outlook from the living room was highlighted. A personal laundry is also the best option.

Outlooks are an important design feature. The concept of a small private garden space with access to a larger public green space can be inferred as the recommended design as it gives the occupant choice. Covered/sheltered transitional spaces should be vital, and addressing weather is important. Transition space for a mobility scooter should be considered when necessary and should be in close proximity to the front door. Semi attached or town house models may be the best model for elderly dwelling as they align with insights about wanting to be close to neighbors but not too close. Integrating other demographic groups in elderly facilities is an important feature to consider and should be incorporated in the best way possible. However, attention to the values and commonalities of these people must be adhered to or organized in the best way possible. Further, the addition of children in elderly complexes is something to further explore. The recommended approach to the pubic waking through the dwelling area would be that as long as the designed environment enables it, it is a positive thing and should be encouraged.

There was a 50/50 split between respondents for and against a spare room. It can be reasoned that if designing for low socio-economic groups where space and money is limited, a communal guest room may be the best option. Wall to wall carpet living rooms tended to be the favored option and consideration into trip hazards is necessary. It can be suggested that the ideal size unit is between 74$90 \mathrm{sqm}$. Open plan living/kitchen/dining was the preferred layout by majority of the respondents. The deviation among the preferences seemed to be a generational element, with those over 35 preferring open plan kitchen/dining and separate living. This finding is compatible with the findings from the 
preceding study where six elderly occupants stated they like to or would like to be able to separate the kitchen from the living space, done so through a breakfast bar. In saying this, the best design may be open plan with the ability for occupants to separate spaces. It is recommended to appropriately consider the proportionality of spaces such as bedroom and lounges dependent on how many people living there, not too large and not too small. This was also recognised in the preceding study.

In regard to the social environment, participants perspectives largely diverged between their preferences for their life now, and for when they are elderly. In saying this, the large majority of respondents thought it would be important in the future to socialize and get along with their neighbours. The design should allow for choice and graduated abilities to socialize, with the ability to retreat back to more private spaces. Points were raised about conflict and tensions in regard to communal spaces, as well as the idea that in principle they seem like a nice idea yet are not always used. These comments were also identified in the preceding study where majority of occupants did not like the idea of a communal space and referred to times when organized communal activities were unsuccessful. However, the literature identified communal spaces and encouraging socialization is very important within elderly facilities. Based on discussions, communal gardens may be used best when occupants also have private gardens. It is suggested that communal facilities and gardens should have some sort of authority as care takers. Once again, future designs must consider the ability for occupants to have choice and a graduated ability to be involved.

The research has identified that choice is a reoccurring theme which is very important. From discussing the layout of the property and gardens, to socializing and privacy, people always referred to wanting the ability to have a different space to 'retreat' to or the option to do something different. Thus, this is something that is essential to consider when designing social elderly housing.

There were a series of implications raised throughout the research. The responses collated during this phase of the research suggest there may be a potential correlation to the theoretical proposition established in the preceding study. The earlier phase of this research (phase 2) posited that there may be a potential for households comprised of different age groups and generations to have specific user preferences. The responses in this study present several examples that validated this hypothesis;

1. In regard to the preferred arrangement of bathrooms, eight respondents were in favor of ensuites and were all under the age of 30 except two (one was 50 and made a cultural observation and one was 37). Further, nine participants expressed a strong dislike towards ensuites. Seven of these participants were over the age of 40 . One outlier was 21 years old, yet their preference was related to spatial efficiency of the additional bathroom. 


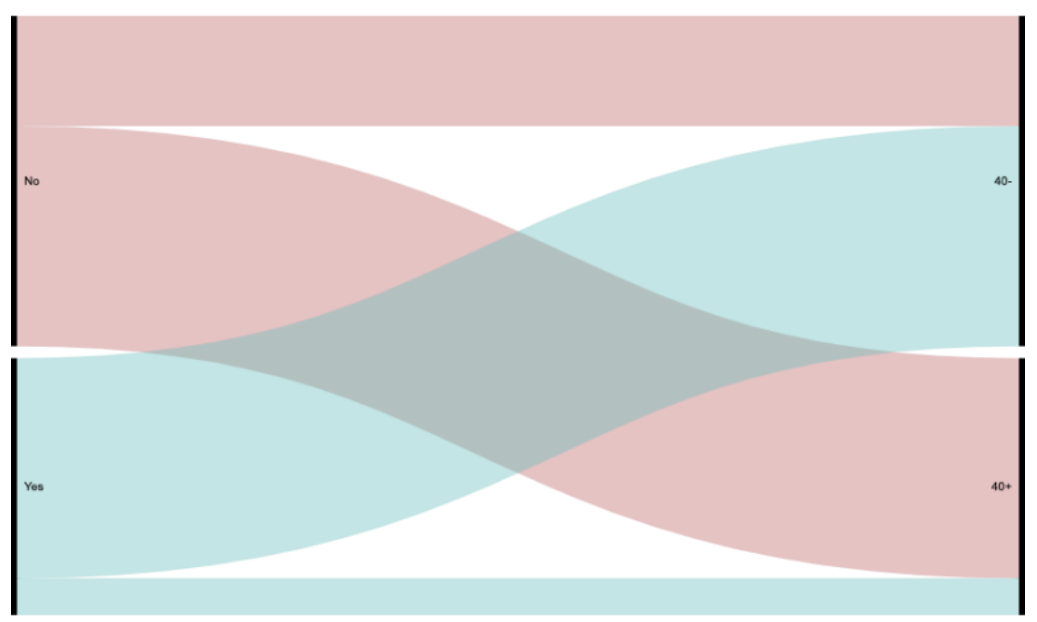

Graph 1: Table showing responses and age in relation to ensuites.

Graph 1 illustrates this pattern. Those that responded that they did not like ensuites were mostly over the age of 40 . Whereas those who were in favour of ensuites were generally under the age of 40.

2. Thirteen participants stated a preference for open plan kitchen/living/dining. Of which, twelve were under the age of 40 and this suggests that this is a layout that is more appealing to younger generations.

These results seemed to endorse the theory that differing user preferences can be attributed to generational reasons. However, there were various occasions where the study illustrated examples that contradicted this hypothesis;

1. Six participants responded they did not want to live in an apartment. Of these, four were under the age of 25 . One might assume that younger people have more familiarity with high density dwellings and therefore more open to the idea of living in apartments, yet these answers negate this assumption.

2. In terms of living in an integrated way with other demographics around in their current immediate community. Participant two (age 25 and flatting) was the only person who did not want this. Ten other participants were also in their 20s and flatting, yet none held this same perspective as participant 2 . This again suggests it is not a generational preference.

Table 1 emphasises that in the current study the user preferences did not seem to be related to age group. As illustrated, across majority of these points, multiple responses were acquired from each age group demonstrating that specific preferences are not correlated to age. Hence it was important to identify other patterns that appeared that may determine why user preferences vary.

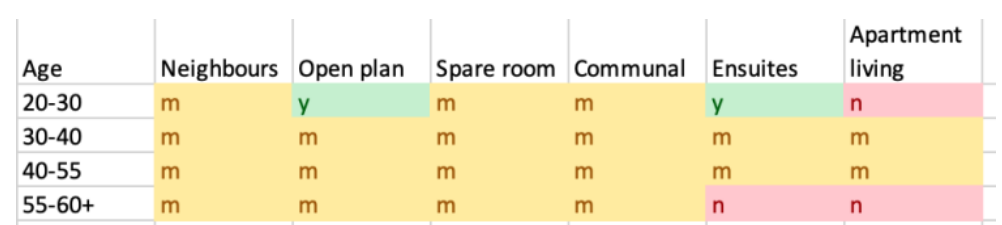

Table 1: Table illustrating the responses across age groups.

$$
\mathrm{y}=\text { yes, } \mathrm{n}=\text { no, } \mathrm{m}=\text { multiple, }
$$


The largest trend identified throughout the present study appeared to be correlated to life stage. Similar user preferences appeared among participants because of their stage in life. That is, whether they are living by themselves, with children or flatting.

\begin{tabular}{|l|l|l|l|l|l|l|l|l|} 
Life stage & Neighbours & Neighbours & Open plan & Open plan & Spare room & Spare room & Communal & Front layout \\
\hline Kids & $\mathrm{y}$ & & $\mathrm{y}(2)$ & $\mathrm{n}(5)$ & $\mathrm{y}(4)$ & $\mathrm{n}(2)$ & $\mathrm{y}$ & $\mathrm{y}$ \\
\hline No kids & $\mathrm{y}(3)$ & $\mathrm{n}(8)$ & $\mathrm{y}(7)$ & $\mathrm{n}(1)$ & $\mathrm{y}(3)$ & $\mathrm{n}(4)$ & $\mathrm{m}$ & $\mathrm{n}$ \\
\hline Flatting & $\mathrm{y}$ & & $\mathrm{y}$ & & $\mathrm{y}(5)$ & $\mathrm{n}(2)$ & $\mathrm{y}$ & \\
\hline
\end{tabular}

Table 2: Table showing the trends based on life stage including yes and no answers.

\begin{tabular}{|c|c|c|c|c|c|}
\hline Life stage & Neighbours & Open plan & Spare room & Communal & Front layout \\
\hline Kids & y & $\mathrm{n}$ & y & $y$ & $y$ \\
\hline Alone & $\mathrm{n}$ & y & $\mathrm{m}$ & $\mathrm{n}$ & $\mathrm{n}$ \\
\hline Partner & $\mathrm{n}$ & $y$ & $\mathrm{~m}$ & $\mathrm{n}$ & $\mathrm{n}$ \\
\hline Flatting & y & $y$ & $y$ & $y$ & \\
\hline
\end{tabular}

Table 3: Table showing the corresponding responses to life stage based on the majority response of each group.

Tables 2 and 3 show all those that commented positively (yes) to wanting to communicate and socialise with their neighbours, and all those that responded negatively (no), and so on with the various points of discussion. The tables demonstrate that there is a strong correlation between user preferences and stage in life. It is not that every single person in the same life stage holds the same perspective, the trend is based on the majority. Table 5 illustrates that those people who live alone, or with a partner tend to have the same user preferences whereas those who have kids tend to have the same user preferences. Those that were flatting tended to have the same perspective, yet this is touched on further on. Examples of this trend occurring through the focus groups are listed below:

1. Eight participants had no expectation to get to know their neighbors. While they were from three different generations, (ages 23-54) they resembled each other in terms of life stage. They are all professionals without children either living by themselves or with a partner. They commented on not needing to be social with their neighbors as they can do this elsewhere and in other situations. Thus, it suggests a pattern about stage in life or their circumstance and therefore no overt desire to be neighbourly. However, for the purpose of the design suggestions, it must be noted that of this eight, only three participants stated they did not believe it would be important to get to know their neighbours in their later years.

2. Six respondents had a preference for an open plan kitchen/dining, but a separate living space. Those that had a preference for this layout were between 35 and 57 . Thus it could be a generational preference. However, four of these have children living with them, therefore suggesting more energy/chaos in their houses. This is of a particular concern, as those that held this point also brought up their children in the conversation at this point. It can be inferred that future preferences may have been altered by the fact that they currently had children living with them.

3. Five participants commented they did not want access to any communal facilities now. They once again said they would prefer to choose to go and socialize in places with people they want to interact with. These participants vary in age (23-54 years) yet they seem to be at similar stages in their lives/potentially with similar values. They are all females who live on their own or with a partner and no children. Once again, for the purpose of design recommendations it 
must be noted that all five were in favour of communal facilities when they are older. However, three of them did note the idea may be more appealing than the functionality.

4. Eight participants commented a spare room was not so important to them. The table below illustrates this pattern.

\begin{tabular}{|l|l|l|l|l|}
\hline LS & $\begin{array}{l}\text { Spare room } \\
\text { no }\end{array}$ & $\begin{array}{l}\text { Spare room } \\
\text { no }\end{array}$ & $\begin{array}{l}\text { Spare room } \\
\text { yes }\end{array}$ & $\begin{array}{l}\text { Spare room } \\
\text { yes }\end{array}$ \\
\hline Age & $30-(6) !$ & $30+(2)$. & $30-(4)$. & $30+(7) !$ \\
\hline Professional y & y & & y \\
\hline Student & & & $y$ & \\
\hline
\end{tabular}

Table 4: Table showing correlations related to spare room preferences.

The table demonstrates that majority (highlighted green) of those who did not believe a spare room was necessary were under the age of 30 and in their professional career, working full time. Additionally, as shown by table 3 above, these respondents also do not have kids and are flatting, living with a partner or by themselves. This may suggest that their experience of the beginning of their professional career and their flatting/high density living experiences is still semi-recent and this has influenced them to believe spare rooms are unnecessary. Whereas those under 30 who thought spare rooms were necessary were students and their experiences living in family homes tended to be more recent. Once again, the stage of life of the participants seems to correlate to their preferences.

The preferences also related to life experience. For example;

5. Six participants (aged 21-41) said they would be happy with any green space they could get. They were all living in some sort of town house or apartment and referred to their recent experiences of not having access to a garden. This suggests their circumstances/life experience may impact the extent of their needs and shape their preferences.

An insightful observation was made in discussions about outdoor space which emphasises this trend. Respondent 20, (age 21) compared being a student with being elderly as you do not have as much money or space. Whereas they stated that perhaps in their mid-life when they have more money they would prefer to have their own garden. This reiterates the idea that preferences vary depending on life stage.

As these results display, the major trend identified throughout the present research is that user preferences tend to be correlated to people's stage of life. Therefore, it is difficult to predict what this means for the designs of future social elderly housing, as clearly life stages will change. However, the extent of the change is unknown. It is reasonable to suggest that those whose preferences appear to be correlated to having children will not have children living with them in the future, thus their preferences will likely differ. Further, it is likely that the user preferences of those who are professionals living on their own or with a partner and thus have similar perspectives because of their flexibility, are likely to change. They will be physically less mobile and may be constrained in this way. What was theorised to be about generations may actually be about the participants life stage. It is this that seems to have impact and influence the perspectives and preferences. This finding illustrates it is difficult to envision future preferences. Yet, there was enough of a consistent agreement for the other specific design preferences that this research can still be considered useful for recommending future designs.

The impact of cultural was also highlighted as another causation for varying user preferences. For example; 
1. This was evident when participant made an observation about ensuites. They asserted that it is a very Kiwi thing to have three bedrooms and only 1 bathroom in a house, and that it is weird. He stated it is particularly important to have the choice when you are older thus essential to have an ensuite.

2. Seven respondents commented on liking the layout of an open style front property with a more private back yard. One of these was American, one was Argentinian and one British and had not lived their whole life in New Zealand. It was mentioned that it was a very NZ thing to have high fences at the front of the property and they missed the more open style environment of their home countries.

An inability to speak about the limitations of social housing was identified as another implication of the research. Participants spoken to were not in the demographic the research is specifically about. This was understood at the beginning of the study, however it became apparent throughout the discussions that people tended to find it difficult to imagine themselves with a limited amount of wealth or assets, as is defined by social housing. When cost was discussed it seemed to relate to people's affluence. It can be reasoned that people with less wealth mentioned cost whereas those with more wealth did not. For example, $50 \%$ of occupants said they did want a spare room. The reasons for this were predominantly because spare rooms often become storage or junk rooms, and not because of cost. Only a limited amount of people spoke to the cost factor. Participants 22 and 23 stated they would both prefer a spare room, however if it would cost more to have a spare room their preference would change. These participants were exchange students from China and Papua New Guinea. It can be assumed that as they are students and not living with their families, they are currently in a lower socio demographic. Another example was established when speaking about the preference for ovens. Most occupants were quick to state their ideal oven, most often a wall fitted oven. However, participant 2 (age 23 and flatting) said she would "take what I can get". This illustrates that the life experience and affluence of people altered their preferences. This was also identified in the phase 2 of this project where the occupants expressed a surprising element of contentment and reluctance to come across as unappreciative. It was assumed that as the occupants of the case study were from a low socio-economic demographic, they felt grateful for the opportunity to live in such an environment, and thus did not want to complain. It can be theorized that this is a user preference trend based on life experience.

\section{Limitations}

It should be noted that this study is not without its limitations. Firstly, in order to identify occupant preferences of elderly housing, a range of generations were analysed, ranging from 21 years old, to 61 years old. This was a limitation as people found it difficult to project an accurate representation of themselves and their preferences later in life. Comments were made such as, "I am unsure if in my old mind I would want this, but my young mind is telling my old self that I should want this." This highlights how people find it difficult to project an accurate representation of themselves in the future and thus answer from a "this is what I would like myself to do in the future." This is of particular concern as no one knows how their needs and wants will actually differ in the future.

Participants only being able to speak about what they know, proved to be a further limitation. Interviews with occupants only consisted of a series of conversation style questions, no physical alternatives were presented. The lack of alternative options, such as diagrams or pictures meant that 
when speaking about unit size, layout of inside and outside, mobility scooter parking and so on, it was difficult to get specific preferences for the best design. Answers were sometimes rather general. However, as these case studies consisted of people who have an informed and experienced perspective of design, it was more successful than the preceding study (phase 2) for bringing critiques and insights.

Another limitation was the organisation of the focus groups. It became apparent that often the participants within a focus group would all agree on the same perspective or take the same angle to answering a question. Further, there were occasions when participants would state their perspective, then after hearing the perspectives of others they modified their opinion. For example, when speaking about living in an integrated way with families, participant 11 spoke about enjoying having the energy of children around and that they would also like that in the future. However, after hearing the perspective of two others only wanting to live with their own age group when they are older, participant 11 reflected and said actually "when I am older, I would want to have people the same age around me." This is particularly interesting as this was the minority perspective across all participants.

While the conversations and reflections within focus groups may have encouraged participants to expand on their perspectives at some points, they may have also had negative impacts by bringing out false perspectives. It would have been interesting to combine all participants in one large group to see how conversations varied.

Additionally, participants spoken to in this study were not necessarily in the demographic that this study is focusing on. Most respondents were well into their professional career which suggests that they are in a comfortable position of wealth. This was a limitation as they tended to have user preferences that reflected this position, often overlooking the concept of social housing in terms of the limitations and sacrifices. Further in order to identify how user preferences differ across multiple generations, the study only interviewed occupants who currently live in Wellington. While there was a very broad selection of ethnic backgrounds, not looking at a variety of people from different cities or countries means the results presented are biased to Wellington. It is likely that people living in rural areas, or more densely populated areas would have varying perceptions.

\section{Further of Research}

These limitations are the basis for the logical next steps in this research which will need to be focused on:

- Presenting occupants with alternative design and layout options of units, to encourage more specific insight into recommendations for the future. 
Howden-Chapman, P., Signal, L. \& Crane, J. (1999) Housing and health in older people: Ageing in place. Social Policy Journal of New Zealand, 13(13):14-30.

Kupperschmidt B. (2000). Multigenerational employees: Strategies for effective management. The Health Care Manager , 19, 65-76. doi:10.1097/00126450-200019010-00011

McDougall L. (2019). Designing social housing for elderly.

Reeder, P. H. (2010) The Theory and Practice of Husserl's Phenomenology. Pathways in phenomenology.Availablefrom:https://books.google.co.nz/books?id=vGnLBAAAQBAJ\&amp;pg=P A21\&amp; dq=phenomenology+definition\&amp; $h l=e n \& a m p ; s a=X \& a m p ; v e d=0 a h U K E w j 33$ pne9avQ AhXCGJQKHbvsCbMQ6AEIKjAD

Statistics New Zealand (2013) Census of Population and Dwellings Dataset [Online] Available from: https:// www.stats.govt.nz/topics/census [Accessed 10th December]

Stewart-Withers, R., Banks, G., McGregor, A., \& Meo-Sewabu, M. (2014). Qualitative research. In R. Scheyvens (Ed.), Development filedwork: A practical guide (pp. 59-80). London, England: Sage. 


\section{Appendix A}

Johnson, A. (2017) The Demand for Social Housing in New Zealand. [Online] The Salvation Army Social Policy \& Parliamentary Unit. Available from: https://www.otago.ac.nz/library/pdf/ Harvard_referencing.pdf [Accessed 2nd December 2018]

This paper explores the large problem of social housing in New Zealand. It defines social housing and explains the scope of the problem, with 150,000 working age people needing social housing and 190,000 older people, with this number forecasted to grow to 270,000 by 2030 . The paper outlines the significant shortage of social housing stock region by region. They provide an analysis suggesting the need for between 1500 and 3500 additional social housing units each year, for at least the next decade.

Kuboshima, K., McIntosh, J. \& Thomas, G. (2018) The Design of Local-Authority Rental Housing for the Elderly That Improves Their Quality of Life. Buildings. [Online] 8 (71) 1-13. Available from: doi:10.3390/ buildings8050071 [Accessed 1st December 2018].

This paper examines what is needed for quality of life for elderly living in rental housing with high care needs. It uses a a qualitative, ethnographic case study approach, examining six elderly people living under this requirement/condition. Themes of quality of life were identified form literature and summarised into 6 key categories, activities and independence, sense of control, privacy, relationships, quality of care and comfort. The analysis found that focusing and acting on these features has the ability to significantly enhance the QoL of elderly people living in these environments. Specifically, consideration for micro-spatial organisation in the lounge and outside space will help allow for different privacy and safety needs swell as promoting a wider range of activities. Thus the layout of the space needs to be flexible to accomodate for different needs. Bathrooms and the individual units should accomodate for the caregiver or those close to the individual by making the space slightly larger. However the study only explored six individuals so further research would help confirm and consolidate these findings.

Taylor, A. (2016) Building Affordable Elderly Housing: How New Zealand's planning system influences market outcomes In: NZPI. NZPI (2016) Over the Rainbow.

This paper focuses on the ageing population in New Zealand and how this changing demographic necessitates the need for a change in housing that will be cater to the needs of this demographic. It explores the issue of the elderly needing specific types of homes and features to cater to their ailments. It explains how the changing population demographics will have significant impacts on the ability of the country to financially support the elderly in the future. As superannuation is one of the only sources of income for many elderly in New Zealand, it does not give them much to live off, thus more are in need of affordable housing. However, because of the current market conditions and the planning rules it is difficult to develop the affordable homes for elderly which are becoming more and more desperately needed. The paper considers how the Resource Management Act (RMA) has influenced the development of affordable elderly housing.

\section{Appendix 2 - Project Outline and Interview Questions}

1. Discussion points about public and private environments

a) Do you like to be able to easily communicate or socialise with your immediate or close neighbours? Would this preference differ in the future?

b) Is it important to you to have privacy from other units?

c) Would you like to have access to communal facilities? For example, flower gardens or vegetable gardens, conservatory/lounge spaces, communal clothes lines, pool, gym?

d) What type of living or dwelling could you see yourself living in? What would make you most content?

e) Would you like to live in an integrated way with families and other demographic groups in neighbouring dwellings?

f) Would the public walking through the dwelling area affect you? 
2. External Environment

a) What kind of connection do you like to establish with the outdoors? For example, do you want an outdoor/gardening area to use or just to look at? Would you like/use a private terrace space Greenery/AstroTurf outside?

b) What transitional spaces are part of your preferred dwelling space or important to you? For example, porch, deck, patio, covered walkway

c) If you required assisted mobility, for example a mobility scooter, where would you see this parked?

3. Finer Grain Details

a) Do you have friends or family members who will stay overnight or for long periods of time? How do you like to be able to accommodate for these people now, how do you think you would like to accommodate for these people in the future? For example, a fold out couch, or a spare bedroom.

b) What is your ideal size unit now? What would your ideal size unit be in the future?

c) In terms of spatial qualities: what features are important to you? For example, height, space generosity, volume?

d) What relationships between rooms and spaces are important? For example I want my private bedroom space tucked away and private; I want the kitchen open and adjacent to the guest space/living room, I want the guest space/living room to seem private.

e) Do you currently have or think there is a potential to have too much of one space and/or not enough of another space?

4. Discussion points about facilities and spatial configuration

a) Do you enjoy cooking and spending a lot of time in the kitchen? Or would you prefer a delivery service for meals?

b) Do you have an oven, how often is that used? Would a microwave or some other conventional oven be just as beneficial? Do you prefer a free-standing oven or a wall fitted oven? Could this differ depending on how many people you are living with?

c) Do you prefer a full ensuite or a bathroom and toilet accessible from the living/guest space? Or would a toilet accessible through the lounge space be helpful?

d) Would you prefer your laundry to be in your own space or in a communal space? 